\title{
Qualitative Risk Management Framework to evaluate environmental risk events in infrastructure projects in developing countries
}

\author{
A. M. Aboushady ${ }^{1} \&$ S. A. R. El-Sawy ${ }^{2}$ \\ ${ }^{1}$ Structural Engineering Department, Faculty of Engineering, \\ Cairo University, Egypt \\ ${ }^{2}$ Middle Eastern Studies Department, Girls' College, \\ Kingdom of Saudi Arabia
}

\begin{abstract}
This paper presents a Qualitative Risk Analysis Framework to identify and prioritize environmental risks encountered in infrastructure projects, which is applied to developing countries. The framework incorporates consensus and quality of experts in the process of evaluating environmental risk events and is composed of (1) Fuzzy Expert System (FES) to determine attributes of experts; (2) Fuzzy Similarity Aggregation Algorithms to aggregate experts' opinions; and (3) three-dimensional prioritization approach to rank the risks, qualitatively. The FES determines an importance weight factor for each expert, based on a set of predetermined qualification attributes. Experts' opinions are aggregated in a linguistic framework, based on the proximity of their opinions on the scale to ensure that their aggregated decision is a result of common agreement. The importance weight factor is combined with the consensus weight factor of each expert in the aggregation process using a scalar modifier and the Euclidean Distance Measure Function is used to determine the linguistic criticality of every environmental risk event. A three-dimensional prioritization approach applies a set of ranking rules to every risk that enables experts to rank and visualize the priority of the risks in a three-dimensional space. The framework contributes to the Construction industry by solving a major problem for project teams in developing countries to qualitatively evaluate environmental risks in a fully supported linguistic framework, using fuzzy logic, which addresses the vagueness and imprecision that exist in the decision-making process. It provides an
\end{abstract}


improvement over other fuzzy qualitative-based models, using FES, instead of relying on an arbitrary assessment of experts' qualifications in aggregating their opinions.

Keywords: fuzzy sets, Fuzzy Expert System, qualitative-based models, risk management.

\section{Introduction}

Risk management is an essential process in planning and developing infrastructure projects, which have great impact on the construction industry. The essentiality of risk management is greater in an industry that is characterized by high levels of uncertain, such as the case of infrastructure construction. Moreover, for instance, according to a recent statistics presented by the World Bank in 2011, the Turkish Construction Industry reached 60.5 Billion USD, which contributes to the Turkish Growth Domestic Product with $4.7 \%$ of the national Growth Domestic Product (GDP) in 2011. Unlikely, there is no adequate research that tackles Environmental Risks, especially in Egypt. Thus, there is a demand to develop this framework to assess Environmental risks in developing countries and specifically in Egypt in order to avoid the imprecision and vagueness inherited in risk analysis.

\section{Literature review}

Risk may have many interpretations and its definition can vary from one situation to another (Markowski and Mannan [1]). Chapman [2] defined risk as "the exposure to the possibility of economic and financial loss, or delay as a consequence of uncertainty associated with pursuing a particular course of action." Many authors have studied risk management from different perspectives. Some researchers have tackled the issue of qualitative risk analysis to prioritize risk events from different perspectives. Al-Daoor [3] studied risk assessment and management of building construction projects in Gaza Strip. Eraky [4] studied risk management of Ministry of Interior construction projects in Egypt. Also, Ragab [5] studied contractor's risk in Lump-Sum Design/Build Contracts in Egypt. Algarnas [6] studied residential construction projects' risks in Saudi Arabia. Finally, Harak [7] studied risk management of BOT projects in Egypt. All the above researchers did not suggest or provide a methodology for determining experts' qualifications participated in the process of determining risk events in order to ensure that experts are qualified to perform such tasks. According to Herrera and Herrera-Viedma [8], "those individuals (experts or decision-makers) are called on to express their opinions on a predetermined set of alternatives in order to select the best one(s)". Most often, infrastructure project teams have difficulty in evaluating environmental risks encountered in their projects, while construction firms depend on expert judgment in assessing these risk factors (Zabaal [9]). According to Elbarkouky and Fayek [10], the two main issues that may affect the decision-making process are "extracting meaningful data from a group of experts, and combining the experts, subject opinions by resolving disagreements." This is the reason why there is a need to develop a framework to 
aggregate experts' opinions in prioritizing environmental risks that can motivate expert judgment and deal with its relative vagueness and imprecision, linguistically. The framework should be also capable of assessing the quality of experts in the decision-making process and it has to enable experts to prioritize the environmental risks, based on their probability of occurrence, impact, and level of detection/control.

\section{Objectives and contributions}

The main objective of this paper is to prioritize different environmental risk events existed in infrastructure development projects. This framework combines Fuzzy Expert System (FES) model with the Fuzzy Similarity Aggregation Model to assess environmental risks in infrastructure Development Projects. The framework provides project teams with a useful tool that incorporates consensus of the project team members in performing environmental risk criticality analysis of infrastructure project with the importance weight of each expert participated in the process of evaluating risks existed in infrastructure projects based on his or her qualifications.

\section{Methodology and model development}

The framework consists of two models: FES, and Fuzzy Similarity Aggregation Model (Figure 1).

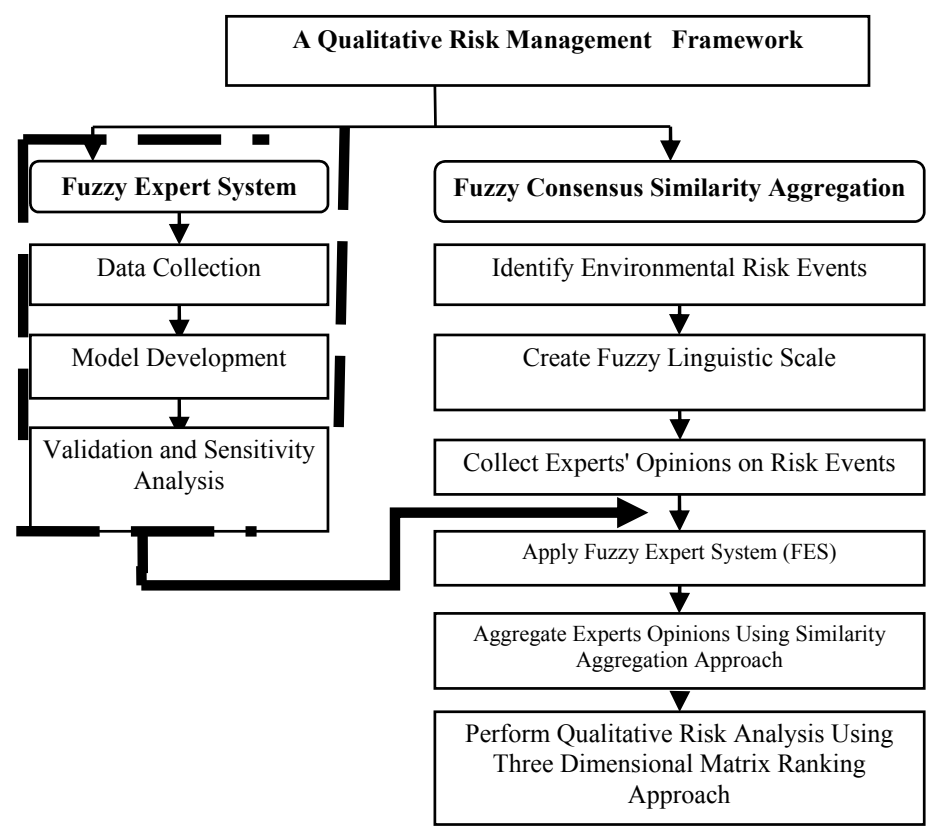

Figure 1: Model development. 


\subsection{Fuzzy Expert System model}

The FES is composed of three stages: (1) data collection and variables' development; (2) FES model development; and (3) validation and sensitivity analysis. Figure 2 illustrates the basic components of the FES.

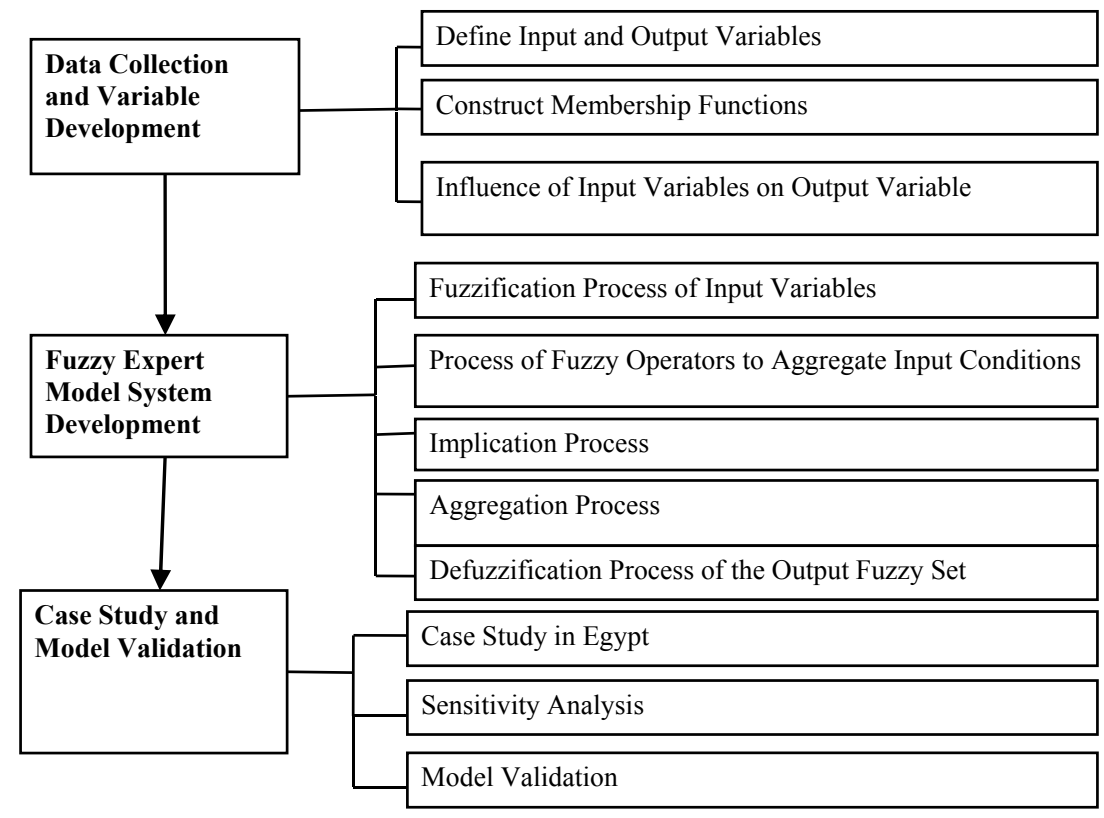

Figure 2: Components of FES model.

\subsubsection{Data collection and variables' development}

The first step in developing the FES model involves defining its input and output variables, developing the scales that are used to define these variables, and defining the linguistic terms describing each of these variables, using experts' judgment. Step two involves constructing the membership functions of the input, and output variables, using the modified horizontal approach coupled with interpolation technique. Step three involves deciding on the relative influence of the input variables on the output variable, which assists on developing the rule base of the FES. In this step, data are collected from experts, using a survey-based questionnaire and a 1-5 likert scale with 1 means "very low influence" and 5 means "very high influence."

\subsubsection{Fuzzy Expert System (FES) model development}

The second stage involves the FES model development, which includes the creation of the FES model that is implemented using FuzzyTECH ${ }^{\circledR}$. FuzzyTECH ${ }^{\circledR}$ software motivates the creation of the knowledge base of the fuzzy-if-then rules, automatically, based on the influence of the input variables on the output variables. 


\subsubsection{Validation and sensitivity analysis}

The third stage involves the validation and sensitivity analysis to test the quality of the FES model. A case study is applied to determine the importance weight factor of a group of Infrastructure experts in Egypt, based on their actual attributes. The output data of the model is to be validated through experts to provide an average assessment of the importance weights of the group of Infrastructure experts. The average percentage error between the outputs of the model and the average rating of experts is calculated to validate the results of the model.

\subsection{Fuzzy Consensus Similarity Aggregation model}

The Fuzzy Consensus Similarity model is composed of six steps.

\subsubsection{Identify critical environmental risk events}

Environmental risk events were determined using literature review and interviews with ten experts each of them had twenty years of experience in construction projects. Experts agreed that environmental risk events can be divided into five categories: Financial and Resource Risks, Geotechnical Risks, Environmental Harm Risks, Electrocution Risks, and Social, and Safety Risks (Table 1).

Table 1: Critical environmental risk events.

\begin{tabular}{|c|c|c|c|}
\hline Risk ID & Risk description & $\begin{array}{l}\text { Risk } \\
\text { ID }\end{array}$ & Risk description \\
\hline \multicolumn{2}{|c|}{ Group (1): Financial, and resource risks } & 15 & Increased erosion rate. \\
\hline 1 & $\begin{array}{l}\text { Delay of the owner progress payment to } \\
\text { contractors. }\end{array}$ & 16 & Unexpected surface conditions. \\
\hline 2 & $\begin{array}{l}\text { Increase in the government restriction to } \\
\text { finance construction companies. }\end{array}$ & \multicolumn{2}{|c|}{ Group (3): Environmental harm risks } \\
\hline 3 & $\begin{array}{l}\text { Decrease in the existence of financially } \\
\text { credible contractors. }\end{array}$ & 17 & $\begin{array}{l}\text { Increased in dust, Noise, and } \\
\text { Vibrations. }\end{array}$ \\
\hline 4 & Increase in design fees. & 18 & $\begin{array}{l}\text { Increased in solid, and water } \\
\text { wastes. }\end{array}$ \\
\hline 5 & Loss due to inflation. & 19 & Existence of toxic and Suffocation. \\
\hline 6 & $\begin{array}{l}\text { Currency devaluation and variable rate } \\
\text { of exchange. }\end{array}$ & \multicolumn{2}{|c|}{ Group (4): Electrocution risks } \\
\hline 7 & Increase in the borrowing interest rate. & 20 & $\begin{array}{l}\text { Existence of electrical Shock } \\
\text { Caused by exposing to Cables, or } \\
\text { Machines carrying electric current. }\end{array}$ \\
\hline 8 & Increase in income taxation. & 21 & $\begin{array}{l}\text { Existence of electrocutions as a } \\
\text { Result of unsafe workers' } \\
\text { conditions. }\end{array}$ \\
\hline 9 & Increase in customs. & \multicolumn{2}{|c|}{ Group (5): Social, and safety risks } \\
\hline 10 & Increase in the price of raw materials. & $\begin{array}{ll}22 & A \\
& \mathrm{e} \\
\end{array}$ & $\begin{array}{l}\text { Availability of compressed gas } \\
\text { explosions. }\end{array}$ \\
\hline 11 & Increase in labor wages. & 23 & Increase in welding accidents. \\
\hline 12 & Increase in the cost of equipment. & 24 & Increase in crane accidents. \\
\hline 13 & Increase in the cost of purchasing land. & 25 & Increase in scaffolding accidents. \\
\hline \multicolumn{2}{|c|}{ Group (2): Geotechnical risks } & 26 & $\begin{array}{l}\text { Decrease in the number of safety } \\
\text { training sessions in the site. }\end{array}$ \\
\hline 14 & Soil degradation. & & \\
\hline
\end{tabular}




\subsubsection{Create fuzzy linguistic scale}

The second step is to create a fuzzy linguistic scale; through which infrastructure project teams can rank different environmental risk factors affecting infrastructure development projects, according to the probability of occurrence, impact, and level of detection, linguistically. In this stage, interviews were held with the fifteen experts, and it was agreed by the experts to use a five-point Likert scale ranging from 1 to 5.1 means "very low", 2 means "low", 3 means "moderate", 4 means "high", and 5 means "very high." Furthermore, interviews were held with experts to decide on different elements of the scales (Table 2) for probability of occurrence, impact, and level of detection, using two-steps Delphi technique. Experts recommended the probability of occurrence and level of detection as well as the environmental risk impact groups as per Table 3 . The process of constructing the membership functions of the input and output variables determine the supports and the initial non-uniform shapes of the membership functions of the experts, using the modified horizontal approach (Marsh and Fayek [11], Elbarkouky and Fayek [10]). Figure 3 illustrates the final shape of membership function "Probability of Occurrence".

Table 2: Group scales representation.

\begin{tabular}{|c|c|c|c|c|c|}
\hline Input variable & $\begin{array}{l}\text { Very } \\
\text { low }\end{array}$ & Low & Medium & High & Very high \\
\hline $\begin{array}{l}\text { Probability of } \\
\text { Occurrence }\end{array}$ & $1-20 \%$ & $21-40 \%$ & $41-60 \%$ & $61-80 \%$ & $81-100 \%$ \\
\hline $\begin{array}{l}\text { Impact group } 1 \\
\text { (subjective } \\
\text { items) }\end{array}$ & 1 & 2 & 3 & 4 & 5 \\
\hline $\begin{array}{l}\text { Impact group } 2 \\
\text { (percentage of } \\
\text { increase) }\end{array}$ & $1-20 \%$ & $21-40 \%$ & $41-60 \%$ & $61-80 \%$ & $81-100 \%$ \\
\hline $\begin{array}{l}\text { Impact group } 3 \\
\text { (value of cost } \\
\text { increase) }\end{array}$ & $\begin{array}{c}1- \\
200000 \mathrm{E} \\
\text { GP }\end{array}$ & $\begin{array}{c}201000- \\
400000 \\
\text { EGP }\end{array}$ & $\begin{array}{c}401000- \\
600000 \\
\text { EGP }\end{array}$ & $\begin{array}{c}601000- \\
800000 \\
\text { EGP }\end{array}$ & $\begin{array}{l}801000- \\
1000000 \\
\text { EGP }\end{array}$ \\
\hline $\begin{array}{l}\text { Impact group } 4 \\
\text { (value of cost } \\
\text { increase) }\end{array}$ & $\begin{array}{c}1-20000 \\
\text { EGP }\end{array}$ & $\begin{array}{c}21000- \\
40000 \\
\text { EGP }\end{array}$ & $\begin{array}{c}41000- \\
60000 \mathrm{EGP}\end{array}$ & $\begin{array}{c}61000- \\
80000 \text { EGP }\end{array}$ & $\begin{array}{c}81000- \\
100000 \mathrm{EGP}\end{array}$ \\
\hline $\begin{array}{l}\text { Level of } \\
\text { detection }\end{array}$ & $1-20 \%$ & $21-40 \%$ & $41-60 \%$ & $61-80 \%$ & $81-100 \%$ \\
\hline
\end{tabular}


Table 3: Environmental risk events groups recommended by experts.

\begin{tabular}{|c|}
\hline Group one: \\
\hline 1. $\quad$ Delay of the owner progress payment to contractors \\
\hline 2. $\quad$ Increase in the government restriction to finance construction companies \\
\hline 3. $\quad$ Decrease in the existence of financially credible contractors \\
\hline 4. $\quad$ Soil degradation \\
\hline 5. $\quad$ Increased erosion rate \\
\hline 6. $\quad$ Unexpected surface conditions \\
\hline 7. $\quad$ Increased in dust, noise, and vibrations \\
\hline 8. Increased in solid, and water wastes \\
\hline 9. Existence of toxic and suffocation \\
\hline 10. Existence of electrical shock caused by exposing to cables, or machines \\
\hline carrying electric current \\
\hline 11. Existence of electrocutions as a result of unsafe workers' conditions \\
\hline 12. Availability of compressed gas explosions \\
\hline \\
\hline Group two: \\
\hline 13. Increase in design fees \\
\hline 14. Loss due to inflation (increase in the project materials, plants, labors) \\
\hline 15. Currency devaluation and variable rate of exchange \\
\hline 16. Increase in the borrowing interest rate \\
\hline 17. Increase in income taxation \\
\hline 18. Increase in customs \\
\hline 19. Increase in welding accidents \\
\hline 20. Increase in crane accidents \\
\hline 21. Increase in scaffolding accidents \\
\hline 22. Decrease in the number of safety training sessions in the site \\
\hline Group three: \\
\hline 23. Increase in the price of raw materials \\
\hline 24. Increase in labor wages \\
\hline 25. Increase in the cost of equipment \\
\hline 26. Increase in the cost of purchasing land \\
\hline
\end{tabular}




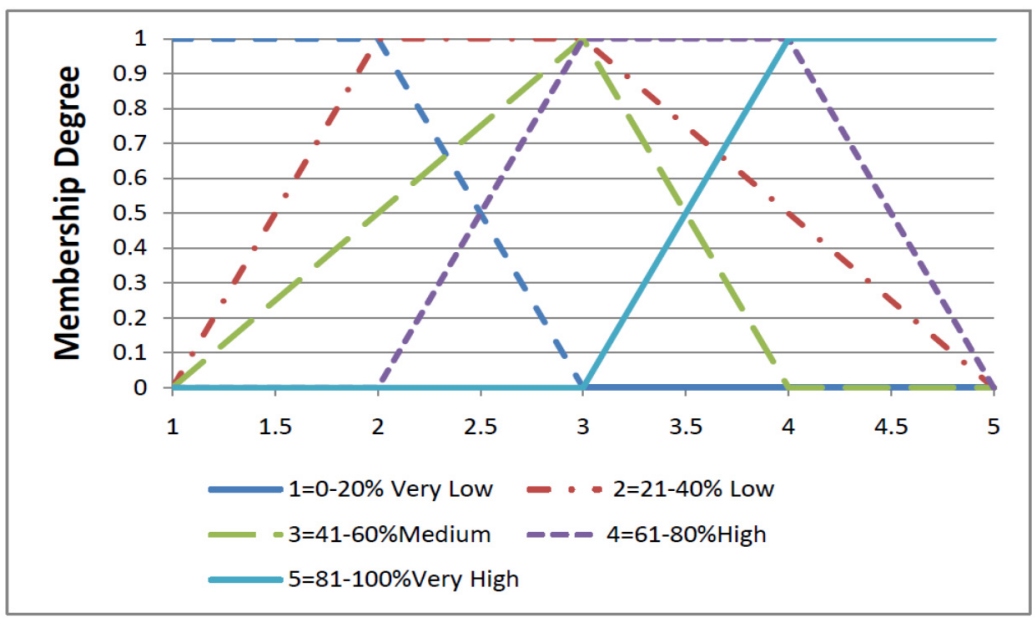

Figure 3: Final shape of the membership function "Probability of Occurrence".

\subsubsection{Collect experts' opinions on environmental risk events}

In order to collect the opinion of experts regarding environmental risk factors affecting Infrastructure Development Projects, a questionnaire-based survey was prepared concerning infrastructure projects in developing countries. The questionnaire is divided into two main sections. The first section contains the demographic information of experts, such as name, role in company, years of participation in risk management process, years of experience in infrastructure projects, and his or her academic records. These experts' attributes assist in developing the FES to calculate the experts' importance weight step (4). The second section of the questionnaire was divided into three main sub-sections. The first sub-section deals with the "Probability of Occurrence" and the expert is asked the question, "What is the probability of occurrence for each environmental risk event?" Please answer the question by placing a check in the scale. The second sub-section deals with the impact of event on infrastructure projects. The expert is asked the question, "What is the impact (cost) for each environmental risk event?" Please answer the question by placing a check in the appropriate box. The third sub-section deals with detection (level of control). The expert was asked the question, "What is the detection (level of control) for each environmental risk event?". Please answer the question by placing a check in the appropriate box. The data collected was then analyzed using the Similarity Aggregation model, which is explained in steps four and five.

\subsubsection{Apply Fuzzy Expert System (FES)}

The fourth step is to apply the FES to calculate an importance weight for each expert participating in the risk assessment process. Table (4) illustrates the experts' attributes, and their importance weights. 
Table 4: Experts' attributes and their importance weights.

\begin{tabular}{cccccc}
\hline Experts & $\begin{array}{c}\text { Years in } \\
\text { infrastructure } \\
\text { projects }\end{array}$ & $\begin{array}{c}\text { Years } \\
\text { in risk } \\
\text { management }\end{array}$ & $\begin{array}{c}\text { Role in } \\
\text { company }\end{array}$ & $\begin{array}{c}\text { Academic } \\
\text { record }\end{array}$ & $\begin{array}{c}\text { Importance } \\
\text { weights }\end{array}$ \\
\hline Expert 1 & $16-20$ & $16-20$ & P. Manager & Master & 0.0455 \\
\hline Expert 2 & $16-20$ & $16-20$ & P. Manager & Master & 0.0290 \\
\hline Expert 3 & $16-20$ & $16-20$ & P. Manager & Master & 0.0353 \\
\hline Expert 4 & $16-20$ & $16-20$ & S.P. Engineer & Master & 0.0320 \\
\hline Expert 5 & $16-20$ & $16-20$ & P. Manager & Bachelor & 0.035 \\
\hline Expert 6 & $16-20$ & $16-20$ & P. Manager & Master & 0.0455 \\
\hline Expert 7 & $16-20$ & $16-20$ & S.P. Engineer & Master & 0.0320 \\
\hline Expert 8 & $16-20$ & $16-20$ & P. Manager & Master & 0.0353 \\
\hline Expert 9 & $16-20$ & $16-20$ & P. Manager & Bachelor & 0.0319 \\
\hline Expert 10 & $16-20$ & $16-20$ & P. Engineer & Bachelor & 0.0227 \\
\hline Expert 11 & $16-20$ & $16-20$ & P. Engineer & Bachelor & 0.0250 \\
\hline Expert 12 & $16-20$ & $16-20$ & P. Manager & Master & 0.0455 \\
\hline Expert 13 & $16-20$ & $16-20$ & P. Manager & Master & 0.0290 \\
\hline Expert 14 & $16-20$ & $16-20$ & P. Manager & Master & 0.0353 \\
\hline Expert 15 & $16-20$ & $16-20$ & S.P. Engineer & Master & 0.0320 \\
\hline Note that in the previous table, P. Manager stands for Project Manager, and S.P. Engineer stands for \\
Senior Project Engineer. & & & &
\end{tabular}

\subsubsection{Aggregate experts opinions using Fuzzy Similarity Aggregation Algorithms}

The first step is to compute the agreement degree $S\left(R_{i}, R_{j}\right)$ between every two standard fuzzy numbers, representing experts' ratings. The agreement degree is the intersection area of the MFs representing the ratings of experts divided by the bounding area, using (1).

$$
\begin{gathered}
S(R i, R j)=\mathcal{L}_{X}(\min \{\mu R i(X), \mu R j(X)\}) d x \\
\int_{X}(\max \{\mu R i(X), \mu R j(X)\}) d x
\end{gathered}
$$

where, $\mu R_{i}$ and $\mu R_{j}$ equals the relevant membership degrees of every element $(X)$ of the fuzzy ratings selected by the experts on the scale.

The second step is to compute the average agreement degree of experts $(A A D)$ by averaging the degrees of similarity of each expert $(i)$ with respect to other experts using (2), where $n$ is the number of experts, and A and B are the two fuzzy trapezoidal numbers selected by experts $i$ and $j$.

$$
A A D E x p e r t(i) \frac{1}{n-1} \sum_{j=1 \text { and } j \neq 1}^{n}(S(A . B))
$$

The third step is to compute the relative agreement degree (RAD) of every expert, using (3).

$$
R A D \operatorname{Expert}(i)=A(E i) / \sum_{i=1}^{n} \mathrm{~A}(\mathrm{Ei})
$$

where $A\left(E_{i}\right)$ is the average level of agreement of an expert with other experts, and it is computed by dividing the sum of his or her agreement degrees with other experts by (n-1) number of experts. 
The fourth step is to calculate the Consensus Degree Coefficient of every expert $\left(C D C_{(i)}\right)$, which combines the relative aggregation weight of expert (RAD (i) obtained from step (3) for every expert with his/her normalized importance weight $\left(w_{i}\right)$ of experts calculated by FES, using (4).

$$
C D C(i)=\beta * W i+(1-\beta) * R A D(i)
$$

The fifth step is to determine the fuzzy number R, which is the sum of the multiplication of the $C D C_{i}$ of each expert by the fuzzy number $R_{i}$ that represents his or her fuzzy rating, using (5).

$$
R=\sum_{i=1}^{n} \quad\left(C D C_{i} * R_{i}\right)
$$

The sixth step is to apply Euclidean Distance Measure to determine the final extent of environmental risk event. In this step, the final linguistic terms that assess the probability of occurrence, impact, and level of detection of every risk event is determined by defining the relevant linguistic term that best matches the aggregated fuzzy number R. This is achieved through computing the Euclidean distance measure, which is proposed by Heilpern [12], to determine the final linguistic term that assesses the critical environmental risk event in those three dimensions by measuring the Euclidean distance between the quadruple $\left(r_{1}, r_{2}, r_{3}, r_{4}\right)$ of the aggregated fuzzy number $R$ and those of the standard fuzzy ratings $S_{(\mathrm{k})}$ on the scale, as in (6).

$$
\operatorname{dg}(\mathrm{R}, \mathrm{S})=\frac{\left(\sum_{\mathrm{i}=1}^{\mathrm{n}}\left|\mathrm{r}_{\mathrm{i}}-\mathrm{s}_{\mathrm{i}}\right|\right)^{1 / \mathrm{p}}}{\mathrm{n}}
$$

where $\mathrm{P}$ equals 2 for the Euclidean distance measure function, $\mathrm{n}$ equals 4 because each fuzzy number is represented by a quadruple, $r_{i}$ is the value of each element of $\mathrm{R}$, and $\mathrm{S}_{\mathrm{i}}$ is the corresponding number forming the quadruple of each of the standard fuzzy ratings $S_{(\mathrm{k})}$ on the scale. The linguistic term that best describes the aggregated fuzzy number $(\mathrm{R})$ is the closest standard fuzzy rating $\mathrm{S}_{(\mathrm{k})}$ to it on the scale.

4.2.5.1 Numerical example First, let $A=\left(a_{1}, a_{2}, a_{3}, a_{4}\right), B=\left(b_{1}, b_{2}, b_{3}, b_{4}\right)$, and $\mathrm{C}=\left(c_{1}, c_{2}, c_{3}, c_{4}\right)$ be three trapezoidal standard fuzzy numbers. Assume that Expert 1 choice is $A$, Expert 2 choice is $B$, and Expert 3 choice is $C$, where $A=(1,1,2,3), B=(1,2,4,5)$, and $C=(2,4,5,5)$.Then, the similarity between the opinions of the three experts is computed using (1), as follows: $S(A, B)=1 / 3.25=0.308, S(A, C)=0.071$, and $S(B, C)=0.250$.

Using (2), the Average Agreement Degree $(A A D)$ among the three experts can be calculated as follows: $A A D_{1}=\frac{1}{3-1} *(0.308+0.250)=0.279$. Similarly, $A A D_{2}=0.190$, and $A A D_{3}=0.161$.

Using (3), the Relative Agreement Degree $(R A D)_{(i)}$ between experts (consensus weight factor) is computed as follows: $R A D_{1}=0.443, R A D_{2}=0.302$, and $R A D_{3}=0.256$. 
Assume that the relative importance weight factors $\left(w_{i}\right)$ of experts were determined by applying the FES to be $0.300,0.300$, and 0.400 , respectively. By assuming equal emphasis of the three experts' consensus weight factors and their importance weight factors, a modifier $\beta=0.5$ is selected and the Consensus Degree Coefficient is computed, using (4): $C D C_{(1)}=(0.300 * 0.500)+$ $(0.443 * 0.500)=0.372$. Similarly, $C D I_{(2)}=0.301$, and $C D I_{(3)}=0.328$.

Note that the total $C D C$ sums to 1.00 (approximation may not show that in the above). Using the previous example and (5), the aggregated fuzzy number( $R$ ), representing the aggregated opinion of experts, would be:

$R_{F S A M}=[0.372 *(1,1,2,3)+0.301 *(1,2,4,5)+0.328 *(2,4,5,5)]=(1.329,2.286$, $3.588,4.261)$.

Using equation (6), the standard fuzzy number representing the linguistic term:

$$
\begin{aligned}
& \mathrm{d}_{1}=\frac{(|1.329-1|+|2.286-1|+|3.588-2|+|4.261-3|)^{0.5}}{4}=0.528 \\
& \mathrm{~d}_{2}=\frac{(|1.329-1|+|2.286-2|+|3.588-3|+|4.261-5|)^{0.5}}{4}=0.348
\end{aligned}
$$

Thus, Expert 2 choice is the chosen one to represent the assessments of the three experts.

\subsubsection{Qualitative risk analysis}

The sixth step is to apply the three dimensional ranking approach that utilizes specific linguistic ranking rules (Abdelgawad [13]) in order to produce a prioritized list of qualified environmental risk events. Table 5 shows the fuzzy prioritization rules. Table 6 illustrates the final list of identified environmental risk events affecting Infrastructure Development Projects.

Table 5: Fuzzy prioritization rules.

\begin{tabular}{ccccc}
\hline $\begin{array}{c}\text { Rule } \\
\text { number }\end{array}$ & $\begin{array}{c}\text { Probability of } \\
\text { occurrence }\end{array}$ & Impact & $\begin{array}{c}\text { Level of } \\
\text { detection }\end{array}$ & $\begin{array}{c}\text { Risk } \\
\text { criticality }\end{array}$ \\
\hline $\mathbf{1}$ & $\mathrm{H}$ & $\mathrm{H}$ & $\mathrm{L}$ & $\mathrm{VH}$ \\
\hline $\mathbf{2}$ & $\mathrm{VH}$ & $\mathrm{VH}$ & $\mathrm{VL}$ & $\mathrm{VH}$ \\
\hline $\mathbf{3}$ & $\mathrm{VH}$ & $\mathrm{VH}$ & $\mathrm{L}$ & $\mathrm{VH}$ \\
\hline $\mathbf{4}$ & $\mathrm{H}$ & $\mathrm{VH}$ & $\mathrm{VL}$ & $\mathrm{VH}$ \\
\hline $\mathbf{5}$ & $\mathrm{VH}$ & $\mathrm{H}$ & $\mathrm{VL}$ & $\mathrm{VH}$ \\
\hline $\mathbf{6}$ & $\mathrm{H}$ & $\mathrm{H}$ & $\mathrm{VL}$ & $\mathrm{VH}$ \\
\hline $\mathbf{7}$ & $\mathrm{H}$ & $\mathrm{M}$ & $\mathrm{L}$ & $\mathrm{H}$ \\
\hline $\mathbf{8}$ & $\mathrm{L}$ & $\mathrm{M}$ & $\mathrm{L}$ & $\mathrm{L}$ \\
\hline $\mathbf{9}$ & $\mathrm{H}$ & $\mathrm{M}$ & $\mathrm{H}$ & $\mathrm{L}$ \\
\hline $\mathbf{1 0}$ & $\mathrm{M}$ & $\mathrm{M}$ & $\mathrm{M}$ & $\mathrm{M}$ \\
\hline $\mathbf{1 1}$ & $\mathrm{L}$ & $\mathrm{L}$ & $\mathrm{H}$ & $\mathrm{VL}$ \\
\hline $\mathbf{1 2}$ & $\mathrm{L}$ & $\mathrm{L}$ & $\mathrm{M}$ & $\mathrm{L}$ \\
\hline $\mathbf{1 3}$ & $\mathrm{M}$ & $\mathrm{M}$ & $\mathrm{VH}$ & $\mathrm{L}$ \\
\hline $\mathbf{1 4}$ & $\mathrm{VL}$ & $\mathrm{VL}$ & $\mathrm{VH}$ & $\mathrm{VL}$ \\
\hline $\mathbf{1 5}$ & $\mathrm{L}$ & $\mathrm{VL}$ & $\mathrm{VH}$ & $\mathrm{VL}$ \\
\hline & & & & \\
\hline
\end{tabular}


Table 6: Final list of identified environmental risk events.

\begin{tabular}{cccccc}
\hline Risk ID & Probability & Impact & Detection & Risk criticality & Rank \\
\hline $\mathbf{5}$ & H & H & L & VH & $\mathbf{1}$ \\
\hline $\mathbf{1 0}$ & VH & VH & VL & VH & $\mathbf{1}$ \\
\hline $\mathbf{1 2}$ & VH & VH & L & VH & $\mathbf{1}$ \\
\hline $\mathbf{1 1}$ & VH & VH & VL & VH & $\mathbf{1}$ \\
\hline $\mathbf{6}$ & H & VH & VL & VH & $\mathbf{1}$ \\
\hline $\mathbf{7}$ & VH & H & VL & VH & $\mathbf{1}$ \\
\hline $\mathbf{3}$ & H & H & VL & VH & $\mathbf{1}$ \\
\hline $\mathbf{2}$ & H & H & VL & VH & $\mathbf{1}$ \\
\hline $\mathbf{4}$ & VH & H & VL & VH & $\mathbf{1}$ \\
\hline $\mathbf{8}$ & H & M & L & H & $\mathbf{2}$ \\
\hline $\mathbf{9}$ & H & M & L & H & $\mathbf{2}$ \\
\hline $\mathbf{1 6}$ & H & M & L & H & $\mathbf{2}$ \\
\hline $\mathbf{2 6}$ & H & M & L & H & $\mathbf{2}$ \\
\hline $\mathbf{1}$ & H & M & L & H & $\mathbf{2}$ \\
\hline $\mathbf{1 4}$ & M & M & M & M & $\mathbf{3}$ \\
\hline $\mathbf{1 8}$ & M & M & M & M & $\mathbf{3}$ \\
\hline $\mathbf{1 5}$ & M & M & M & M & $\mathbf{3}$ \\
\hline $\mathbf{1 7}$ & M & M & M & M & $\mathbf{3}$ \\
\hline $\mathbf{1 9}$ & L & M & L & L & $\mathbf{4}$ \\
\hline $\mathbf{2 0}$ & L & L & M & L & $\mathbf{4}$ \\
\hline $\mathbf{2 1}$ & M & M & VH & L & $\mathbf{4}$ \\
\hline $\mathbf{2 3}$ & H & M & H & L & $\mathbf{4}$ \\
\hline $\mathbf{2 4}$ & L & M & L & L & $\mathbf{4}$ \\
\hline $\mathbf{1 3}$ & L & VL & VH & VL & $\mathbf{5}$ \\
\hline $\mathbf{2 2}$ & L & L & H & VL & $\mathbf{5}$ \\
\hline $\mathbf{2 5}$ & VL & VL & VH & VL & $\mathbf{5}$ \\
\hline & & & & & \\
\hline & & & & & \\
\hline & & & & & \\
\hline
\end{tabular}

\section{Conclusion}

In this paper, a Qualitative Risk Management Framework was proposed to identify, and qualify environmental risks encountered in Infrastructure Development Projects. The framework incorporated consensus, and quality of experts in the process of evaluating environmental risk factors affecting infrastructure projects. Environmental risks were identified through literature review and experts' interviews and were prioritized using Three-Dimensional Matrix Ranking Approach. Consensus weight factor for each expert participated in the risk assessment process was determined, using the Fuzzy Consensus Similarity Aggregation model. The findings of the Qualitative Risk Management Framework in terms of highly ranked environmental risk events will be further quantified using the Fuzzy Fault, and Event Trees Model. The framework provides an improvement over the previous risk management models by incorporating the experts' qualifications, and consensus weight factor of experts in evaluating environmental risks in Infrastructure projects in qualitative manner. 


\section{References}

[1] Markowski, A. S. and Mannan, M. S. "Fuzzy risk matrix." Journal of Hazardous Materials, 159(1), pp. 152-157, 2008.

[2] Chapman, R. J. "The effectiveness of working group risk identification and assessment techniques", International Journal of Project Management, 16(6), pp. 333-343, 1998.

[3] Al-Daoor, M.Z. "Risk Assessment and Management of Building Construction Projects in Gaza Strip". Master Thesis Dissertation, Faculty of Engineering, Cairo University, Giza, Egypt, 2010.

[4] Eraky, Y.W. "Risk Management of Ministry of Interior Construction Projects in Egypt". Master Thesis Dissertation, Faculty of Engineering, Cairo University, Giza, Egypt, 2010.

[5] Ragab, M.Y. "Contractor's Risk in Lump-Sum Design/Build Contracts", Master of Science Thesis, Structural Engineering Department, Cairo University, Egypt, 2003.

[6] Algarnas, A.M. "Residential Construction Projects Risk in Saudi Arabia", Master Thesis Dissertation, Faculty of Engineering, Cairo University, Giza, Egypt, 2007.

[7] Harak, I.A. "Risk Management of the BOT Projects in Egypt", Master Thesis Dissertation, Faculty of Engineering, Cairo University, Giza, Egypt, 2002.

[8] Herrera, F., and Herrera-Viedma, E. "Linguistic decision analysis: steps for solving decision problems under linguistic information." Fuzzy Sets and Systems, 115(1), pp. 67-82, 2000.

[9] Zabaal, N.Y. "Risk Management of Pipeline Infrastructure Projects in Egypt", Master of Science Thesis, Structural Engineering Department, Cairo University, Egypt, 2007.

[10] Elbarkouky, M. and Fayek, A. R. "Fuzzy Similarity Consensus Model for Early Alignment of Construction Project Teams on the Extent of Their Roles and Responsibilities." Journal of Construction Engineering and Management, 137(6), 432-441, 2011.

[11] Marsh, K, and Fayek, A.R. "Fuzzy Expert System to Assist Surety Underwriters in Evaluating Construction Contractors for Bonding" Journal of Construction Engineering and Management, 136(11), pp. 1219-1235, 2010.

[12] Heilpern, S. "Representation and application of fuzzy numbers", Fuzzy Sets, 91(2), pp. 259-268, 1997.

[13] Abdelgawad, M. "Hybrid Decision Support System for Risk Criticality Assessment and Risk Analysis." Thesis Dissertation, Faculty of Graduate Studies and Research, Department of Civil and Environmental Engineering, University of Alberta, Edmonton, Alberta, 2011. 